\title{
Symposium (IJ)
}

\author{
Head Injury
}

Chairman :

Prof. Y. Asano

Kumamoto Univ.

\section{Head Injury.}

T. KUDO

Dept. of Surg., Keio Univ. School of Med.

The speaker delivered his view on how to treat cases of severe head injury in the acute stage. The following two items were the most important parts of his speech.

1) Treatment of subdural hematoma.

He disclosed results of follow-up studies of patients whose subdural hematoma had been evacuated by the irrigation method through a few burr holes, and he confirmed the advantage of this method in comparison with the conventional large bone flap technique.

2) Treatment of cerebral contusion.

Induced hypothermia was applied on the cases of severe cerebral contusion, and good results were obtained.

Problems on the dehydration therapy and fluid administration were also discussed by him.

\section{L2. On the Pathogenis of the Chronic Subdural Hematoma.}

\section{S. KoNDO}

Tokyo Rosai Hospital

From the clinical study on 21 cases of the chronic subdural hematoma, following discussion is presented on the pathogenesis of the condition.

In looking over the case histories of chronic subdural hematoma, there are 